\title{
Four Isostructural 3d-4f Mixed Metal Organic Frameworks and Their Magnetic Properties
}

\author{
Marie L. Mortensen, Abigail L. Lewis, Gregory McCandless and Kenneth J. Balkus, Jr.*
}

\author{
Department of Chemistry and Biochemistry, The University of Texas at Dallas, $800 \mathrm{~W}$ Campbell Rd., Richardson, \\ TX 75080, USA; Marie.Mortensen@UTDallas.edu (M.L.M.); all170130@utdallas.edu (A.L.L.); \\ GTM130130@utdallas.edu (G.M.) \\ * Correspondence: balkus@utdallas.edu
}

Citation: Mortensen, M.L.; Lewis, A.L.; McCandless, G.; Balkus, K.J., Jr. Four Isostructural 3d-4f Mixed Metal Organic Frameworks and Their Magnetic Properties. Crystals 2021, 11, 1547. https://doi.org/10.3390/ cryst11121547

Academic Editors: Alexander Pöthig, Alexandre Abhervé and Maria Laura Mercuri

Received: 2 November 2021 Accepted: 7 December 2021 Published: 10 December 2021

Publisher's Note: MDPI stays neutral with regard to jurisdictional claims in published maps and institutional affiliations.

Copyright: (c) 2021 by the authors. Licensee MDPI, Basel, Switzerland. This article is an open access article distributed under the terms and conditions of the Creative Commons Attribution (CC BY) license (https:// creativecommons.org/licenses/by/ $4.0 /)$.

\begin{abstract}
Four new isostructural 3d-4f mixed metal organic frameworks (MOFs) $\mathrm{Cu} \mathrm{Gd}_{2}(\mathrm{BDC})_{4}$ compound 1, $\mathrm{Cu} \mathrm{Ho} 2(\mathrm{BDC})_{4}$, compound 2, $\mathrm{Cu} \mathrm{Eu} 2(\mathrm{BDC})_{4}$, compound 3, and $\mathrm{Cu} \mathrm{Dy} 2(\mathrm{BDC})_{4}$, compound 4 were successfully synthesized. The structure, stability, and magnetic properties were analyzed. Each MOF has two lanthanide ions and one copper ion node with terephthalic acid as the organic linker. The lanthanide ions form a dimer with each having a capped trigonal prismatic geometry while the copper ion has a square planar geometry. Each of these MOFs shows varying degrees of antiferromagnetic interactions.
\end{abstract}

Keywords: metal organic frameworks (MOFs); mixed metal; synthesis; magnetism; antiferromagnetic

\section{Introduction}

Research in the area of metal organic frameworks, or MOFs has continued to expand due to many different applications including gas storage [1], gas separation [2], catalysis [3], and sensors [4]. There is also growing interest in ionic conductivity [5] and the magnetic properties of MOFs [6]. MOF research has largely been on single transition metal systems with fewer examples of mixed metal systems, especially with transition metals and lanthanides [7]. Lanthanides are known for their unique luminescent [8] and magnetic properties [9]. When lanthanides are combined with transition metals, the weak magnetic coupling found in lanthanides [10] can strengthen into bulk magnetics [11], create strong magnetocaloric effects [12], and result in single molecular magnetics [13]. Additionally, the high coordination numbers of lanthanides combined with the lack of stereochemical preference in comparison to transition metals increases the number of topographies possible [14]. Unfortunately, the differences in the reactivity of transition metals and lanthanides makes the synthesis of such mixed metal MOFs difficult. The nature of their reactivities often leads to homometallic coordination polymers of both metals [15,16].

The lanthanide-based materials that contain $\mathrm{Gd}^{3+}, \mathrm{Eu}^{3+}$, and $\mathrm{Tb}^{3+}$ often exhibit strong paramagnetic properties which have a variety of applications [17]. Lanthanides such as $\mathrm{Gd}^{3+}$ have large spin only magnetic moments which have been used as MRI contrasting agents [18]. Throughout the years, microporous frameworks such as zeolites [19] and MOFs have been used as drug delivery systems as well as MRI contrast agents [20,21]. Paramagnetic guest molecules like oxygen can be encapsulated in MOFs resulting in magnetic coupling [22].

The present study involves the synthesis of four new isostructural bimetallic MOFs. They contain either two gadolinium, holmium, europium, or dysprosium metal ions and one copper center using terephthalic acid as the organic linker. Terephthalic acid is a common organic linker for MOFs due to its cheap, rigid and multidentate nature [23]. The thermal stability, crystalline structure, and magnetic properties of these four new MOFs are discussed below. 


\section{Materials and Methods}

\subsection{Materials}

All chemicals were used as purchased without further purification. Gadolinium nitrate hexahydrate $(99.9 \%)$ was purchased from Strem Chemicals (Newburyport, MA, USA), copper (II) nitrate trihydrate $(99.5 \%)$ was purchased from Strem Chemicals, holmium (III) nitrate pentahydrate $(99.9 \%)$ was purchased from Strem Chemicals, terephthalic acid was purchased from Eastman, $\mathrm{N}^{\prime} \mathrm{N}^{\prime}$ dimethylformamide (DMF) was purchased from Fisher Chemical, europium (III) nitrate hexahydrate $(99.9 \%)$ was purchased from Strem chemicals, dysprosium (III) nitrate pentahydrate $(99.9 \%$ ) was purchased from Alfa Aesar (Ward Hill, MA, USA), and concentrated nitric acid was purchased from Fisher Scientific (Hamptom, VA, USA).

\subsection{Instrumental Methods}

Low-temperature single-crystal X-ray diffraction experiments (either at $\mathrm{T}=100 \mathrm{~K}$ or $\mathrm{T}=110 \mathrm{~K}$ ) were carried out on colorless crystalline fragments (all crystallized in DMF) of compound 1 (Size: $\sim 0.05 \times 0.05 \times 0.01 \mathrm{~mm}^{3}$ ), compound $\mathbf{2}$ (Size: $\sim 0.14 \times 0.12 \times 0.06 \mathrm{~mm}^{3}$ ), compound 3 (Size: $\sim 0.07 \times 0.06 \times 0.02 \mathrm{~mm}^{3}$ ), and compound 4 (Size: $\sim 0.05 \times 0.05 \times$ $0.01 \mathrm{~mm}^{3}$ ) using a Bruker Kappa D8 Quest diffractometer (Incoatec microfocus Mo K $\alpha$ radiation source (Bruker, Billerica, MA, USA), Oxford Cryosystems cryostream (Oxford Cryosystems, Long Hanborough, UK), and Photon II CPAD detector (Bruker, Billerica, MA, USA)). Both datasets for these experiments were integrated with Bruker SAINT, scaled with Bruker SADABS (multi-scan absorption correction), and evaluated for space group selection with Bruker XPREP. A preliminary model was generated with SHELXT (intrinsic phasing method), [24] and anisotropic least-squares refinement was carried out with SHELXL [25]. All hydrogen atoms were refined in "riding" atomic sites.

The powder X-ray diffraction was performed with a Rigaku Ultima IV X-ray diffractometer (Tokyo, Japan), using a $\mathrm{Cu} \mathrm{K} \alpha$ radiation at room temperature by scanning over a range of $2 \theta=5-40^{\circ}$ with a scan rate of $1^{\circ} / \mathrm{min}$. The simulated powder XRD patterns were generated from the CIF files using Mercury. The thermogravimetric (TGA) analysis was collected on a SDT Q600 (TA Instruments, New Castle, DE, USA) from room temperature to $1073 \mathrm{~K}$ at a heating rate of $10 \mathrm{~K}$ from $383 \mathrm{~K}$ till $1073 \mathrm{~K}$. The magnetic data for 1, 2, and 4 was collected on a Quantum Design Physical Properties Measurement System from temperatures of $2 \mathrm{~K}$ to $300 \mathrm{~K}$ with a magnetic field of 1000 Oe. The magnetic data for 3 was collected on a Quantum Design Magnetic Properties Measurement System from temperatures of $2 \mathrm{~K}$ to $300 \mathrm{~K}$ with a magnetic field of 1000 Oe.

\subsection{Synthesis}

$\mathrm{C}_{38} \mathrm{H}_{30} \mathrm{CuGd}_{2} \mathrm{~N}_{2} \mathrm{O}_{18}, 2\left(\mathrm{C}_{3} \mathrm{H}_{7} \mathrm{NO}\right.$ ) (Compound $\left.1, \mathrm{Cu} \mathrm{Gd}_{2}(\mathrm{BDC})_{4}\right)$-Terephthalic acid (29.4 mg, $1.79 \times 10^{-4} \mathrm{~mol}, 4 \mathrm{eq}$.), copper nitrate trihydrate $\left(10.8 \mathrm{mg}, 4.47 \times 10^{-5} \mathrm{~mol}, 1 \mathrm{eq}.\right)$, and gadolinium nitrate hexahydrate $\left(41.1 \mathrm{mg}, 9.11 \times 10^{-5} \mathrm{~mol}, 2 \mathrm{eq}\right.$.) were dissolved in DMF $(15 \mathrm{~mL})$. Concentrated nitric acid $(0.3 \mathrm{~mL})$ was added to the blue solution. The blue solution was transferred to a $23 \mathrm{~mL}$ Teflon lined autoclave and heated under autogenous pressure for 3 days at $393 \mathrm{~K}$. The solution was cooled to room temperature, and the blue crystals were washed with DMF, and dried at $353 \mathrm{~K}$, resulting in a $68.6 \%$ yield.

$\mathrm{C}_{38} \mathrm{H}_{30} \mathrm{CuHo}_{2} \mathrm{~N}_{2} \mathrm{O}_{18}, 2\left(\mathrm{C}_{3} \mathrm{H}_{7} \mathrm{NO}\right.$ ) (Compound 2, $\mathrm{Cu} \mathrm{Ho} 2(\mathrm{BDC})_{4}$ )-This synthesis was performed under the same conditions as 1 with gadolinium nitrate hexahydrate replaced with holmium nitrate pentahydrate $\left(41.6 \mathrm{mg}, 9.22 \times 10^{-5} \mathrm{~mol}\right)$ This resulted in $53.3 \%$ yield.

$\mathrm{C}_{38} \mathrm{H}_{30} \mathrm{CuEu}_{2} \mathrm{~N}_{2} \mathrm{O}_{18}, 2\left(\mathrm{C}_{3} \mathrm{H}_{7} \mathrm{NO}\right.$ ) (Compound 3, $\mathrm{Cu} \mathrm{Eu}_{2}(\mathrm{BDC})_{4}$ )-This synthesis was performed under the same conditions as $\mathbf{1}$ with gadolinium nitrate hexahydrate replaced with europium (III) nitrate hexahydrate $\left(39.7 \mathrm{mg}, 8.900 \times 10^{-5} \mathrm{~mol}\right)$. This resulted in a $39.1 \%$ yield.

$\mathrm{C}_{38} \mathrm{H}_{30} \mathrm{CuDy}_{2} \mathrm{~N}_{2} \mathrm{O}_{18}, 2\left(\mathrm{C}_{3} \mathrm{H}_{7} \mathrm{NO}\right)$ (Compound 4, Cu Dy 2 (BDC) $)_{4}$ - - This synthesis was performed under the same conditions as $\mathbf{1}$ with gadolinium (III) nitrate hexahydrate 
replaced with dysprosium (III) nitrate pentahydrate $\left(39.5 \mathrm{mg}, 9.01 \times 10^{-5} \mathrm{~mol}\right)$. This resulted in an $84.5 \%$ yield.

\section{Results and Discussion}

\subsection{Synthesis}

Blue diamond-shaped crystals of compounds 1, 2, 3, and 4 were synthesized under hydrothermal conditions. Using $\mathrm{N}^{\prime} \mathrm{N}^{\prime}$ dimethylformamide as the solvent, the lanthanide ions $\left(\mathrm{Gd}^{3+}, \mathrm{Ho}^{3+}, \mathrm{Eu}^{3+}\right.$, and $\left.\mathrm{Dy}^{3+}\right)$ and $\mathrm{Cu}^{2+}$ ions reacted in solution containing terephthalic acid (DBC) and nitric acid to form four isostructural novel MOFs $\left[\mathrm{Ln}_{2} \mathrm{Cu}(\mathrm{DCB})_{4}(\mathrm{DMF})_{2}\right.$ 2(DMF) [Ln = Gd (1), Ho (2), Eu (3), and Dy (4)], as shown in Figures 1a and S1.

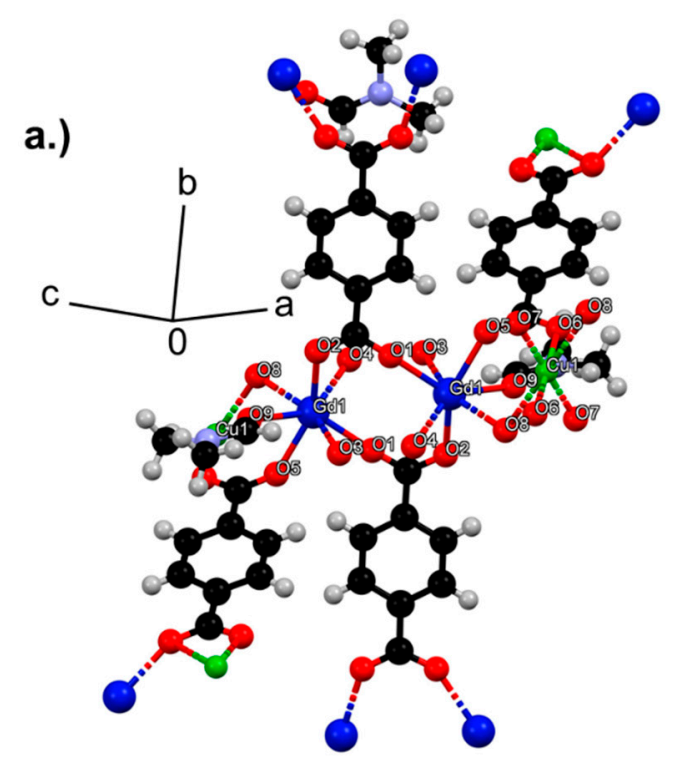

b.)

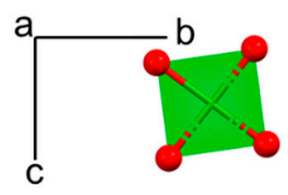

c.)

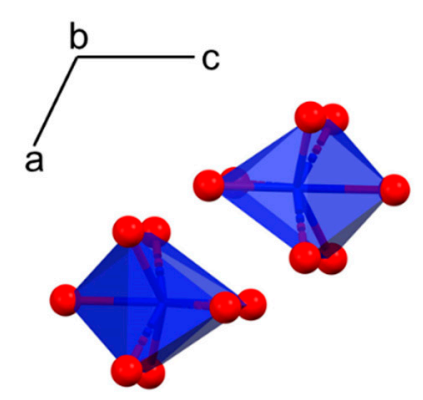

Figure 1. The colors for elements are as follows: gadolinium (blue), copper (green) oxygen (red), carbon (black), nitrogen (purple), hydrogen (white). (a) View of basic unit cell of Compound 1. (b) Coordination environment of a square planar copper. (c) Coordination environment of the lanthanide ions showing a trigonal prismatic coordination.

\subsection{Single Crystal Analysis}

\subsubsection{Structural Analysis of 1}

The framework for compound 1 shows the oxygen atoms of six terephthalic acid ligands are coordinated in a trigonal prismatic fashion to the Gd metal centers (Gd1-O1

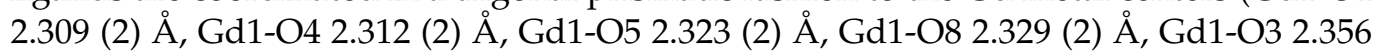
(2) $\AA$, and Gd1-O2 2.361 (2) $\AA$ ). As shown in Figure 1b, the local coordination environment of each Gd metal center is also capped by a seventh oxygen atom of a DMF ligand (Gd1-O9 2.373 (2) ̊). Four terephthalic acid ligands, via $\mu_{2}$-bridging carboxylate substituents, link a pair of Gd metal centers together (Gd1 . . Gd1 interatomic distance of 4.1715 (8) $\AA$ ). Additionally, there is a four-coordinate square planar $\mathrm{Cu}$ coordinated to the oxygen atoms of 4 terephthalic acid ligands (see Figure 1c, Cu1-O6 (×2) 1.946 (2) $\AA$ and Cu1-O7 (×2) 1.964 (2) $\AA$ ). The $\mathrm{Cu}$ metal centers are linked to the Gd metal centers by $\mu_{2}$-bridging carboxylates from two terephthalic acid ligands (Gd1 Cu1 interatomic distance of 4.089 (1) $\AA$ ). The hydrogens atoms were inferred from the neighboring atoms.

\subsubsection{Structure Analysis of 2}

In the isostructural Ho analogue, compound 2, there is a similar seven-coordinate rare earth local environment (Ho1-O1 2.267 (2) $\AA$, Ho1-O4 2.279 (2) $\AA$, Ho1-O5 2.287 (2) $\AA$,

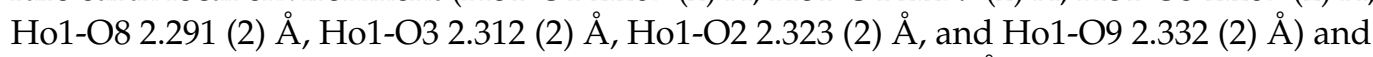
four-coordinate Cu local environment (Cu1-O6 (×2) $1.944(2) \AA$ and Cu1-O7 (×2) 1.959 


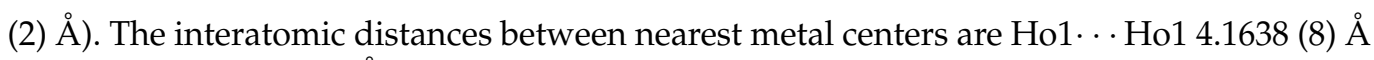
and Ho1 Cu1 4.061 (1) A. The hydrogen atoms were inferred from the neighboring atoms.

\subsubsection{Structure Analysis of 3}

For the $\mathrm{Eu}$ analogue, compound 3 , there is also a seven-coordinate rare earth local environment (Eu1-O1 2.320 (3) $\AA$, Eu1-O4 2.321 (3) $\AA$, Eu1-O5 2.332 (3) $\AA$, Eu1-O8 2.342

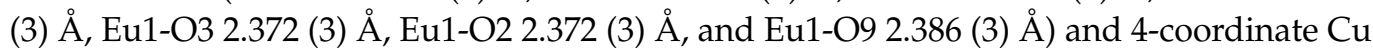
local environment (Cu1-O6 (×2) 1.953 (4) $\AA$ and Cu1-O7 (×2) 1.965 (4) $\AA$ ). The interatomic distances between nearest metal centers are Eu1 ‥Eu1 4.1763 (9) $\AA$ and Eu1 Cu1 4.088 (1) Å. The hydrogen atoms were inferred from the neighboring atoms.

\subsubsection{Structure Analysis of 4}

Lastly, the Dy analogue, compound 4 contains a seven-coordinate rare earth local environment (Dy1-O1 2.273 (4) $\AA$, Dy1-O4 2.285 (3) $\AA$, Dy1-O5 2.295 (3) $\AA$, Dy1-O8 2.305

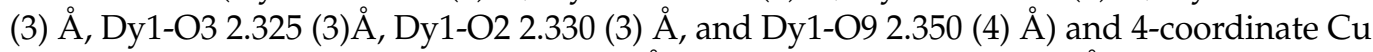
local environment (Cu1-O6 (×2) 1.942 (3) $\AA$ and Cu1-O7 (×2) 1.958 (3) $\AA$ ). The interatomic distances between the nearest metal centers are Dy1 ‥D Dy1 4.160 (2) $\AA$ and Dy1 . . Cu1 4.076 (2) A. The hydrogen atoms were inferred from the neighboring atoms. The CCDC numbers for compounds 1, 2, 3, and 4 are 1952053, 1952054, 2120901, and 2120902 respectively. The XRD parameters and data for compounds $\mathbf{1}, \mathbf{2}, \mathbf{3}$, and 4 are shown in Tables 1 and S1.

Table 1. Single-crystal XRD data for compounds 1, 2, 3, and 4.

\begin{tabular}{|c|c|c|c|c|}
\hline & $\mathrm{Cu} \mathrm{Gd} 2\left(\mathrm{BDC}_{4}\right.$ & $\mathrm{Cu} \mathrm{Ho} \mathrm{Ho}_{2}(\mathrm{BDC})_{4}$ & $\mathrm{Cu} \mathrm{Eu_{2 } ( B D C ) _ { 4 }}$ & $\mathrm{Cu} \mathrm{Dy}_{2}(\mathrm{BDC})_{4}$ \\
\hline Chemical formula & $\begin{array}{c}\mathrm{C}_{38} \mathrm{H}_{30} \mathrm{CuGd}_{2} \mathrm{~N}_{2} \mathrm{O}_{18} \\
2\left(\mathrm{C}_{3} \mathrm{H}_{7} \mathrm{NO}\right)\end{array}$ & $\begin{array}{c}\mathrm{C}_{38} \mathrm{H}_{30} \mathrm{CuHo}_{2} \mathrm{~N}_{2} \mathrm{O}_{18} \\
2\left(\mathrm{C}_{3} \mathrm{H}_{7} \mathrm{NO}\right)\end{array}$ & $\begin{array}{c}\mathrm{C}_{38} \mathrm{H}_{30} \mathrm{CuEu}_{2} \mathrm{~N}_{2} \mathrm{O}_{18} \\
2\left(\mathrm{C}_{3} \mathrm{H}_{7} \mathrm{NO}\right)\end{array}$ & $\begin{array}{c}\mathrm{C}_{38} \mathrm{H}_{30} \mathrm{CuDy}_{2} \mathrm{~N}_{2} \mathrm{O}_{18} \\
2\left(\mathrm{C}_{3} \mathrm{H}_{7} \mathrm{NO}\right)\end{array}$ \\
\hline $\mathbf{M}$ & 1326.87 & 1342.23 & 1316.29 & 1337.37 \\
\hline Crystal System & Monoclinic & Monoclinic & Monoclinic & Monoclinic \\
\hline Space Group & $\mathrm{P} 2_{1} / n$ & $P 2_{1} / n$ & $P 2_{1} / n$ & $P 2_{1} / n$ \\
\hline$a / \AA$ & $11.798(3)$ & $11.728(3)$ & $11.806(3)$ & $11.757(4)$ \\
\hline$m b / \AA$ & $17.390(4)$ & $17.305(4)$ & $17.516(5)$ & $17.289(4)$ \\
\hline$c / \AA$ & $12.804(3)$ & $12.808(3)$ & $12.802(3)$ & $12.783(5)$ \\
\hline$\beta / \AA$ & $115.285(8)$ & $115.108(8)$ & $115.578(7)$ & $114.95(2)$ \\
\hline$V / \AA^{3}$ & $2375.4(10)$ & $2353.9(10)$ & $2388.1(10)$ & $2355.7(14)$ \\
\hline $\mathrm{T} / \mathrm{K}$ & $100(2)$ & $100(2)$ & $110(2)$ & $110(2)$ \\
\hline $\mathbf{Z}$ & 2 & 2 & 2 & 2 \\
\hline$\lambda / \AA$ & 0.71073 & 0.71073 & 0.71073 & 0.71073 \\
\hline$\mu(\mathrm{MoK} \alpha) / \mathrm{mm}^{-1}$ & 3.29 & 3.86 & 3.12 & 3.67 \\
\hline $\mathbf{R}_{\text {int }}$ & 0.037 & 0.054 & 0.069 & 0.074 \\
\hline Reflection Measured & 57,097 & 55,556 & 75,255 & 33,679 \\
\hline Independent Reflections & 7244 & 7178 & 5505 & 5423 \\
\hline Parameters & 326 & 327 & 326 & 327 \\
\hline Reflections with $I>2 \sigma(I)$ & 6742 & 6171 & 4805 & 4154 \\
\hline Final $\mathrm{R}$ value $(I>2 \sigma(I))$ & 0.031 & 0.028 & 0.039 & 0.037 \\
\hline Final $R w\left(F^{2}\right)(I>2 \sigma(I))$ & 0.056 & 0.048 & 0.087 & 0.068 \\
\hline Final $R$ value (all data) & 0.035 & 0.038 & 0.048 & 0.059 \\
\hline$R w\left(F^{2}\right)$ (all data) & 0.057 & 0.052 & 0.091 & 0.076 \\
\hline Goodness of fit on $F^{2}$ & 1.20 & 1.07 & 1.11 & 1.04 \\
\hline
\end{tabular}

The lanthanides within the structures formed dimers, which is very common in MOFs with lanthanides formed using a one-pot synthesis [26]. These dimers form through a process known as ligand-controlled hydrolysis. When hydrated lanthanide salts are reacted in the presence of a base and an appropriate ligand, e.g., containing carboxylates, the formation of lanthanide clusters is driven [27]. While this synthesis is performed with DMF and not water, the lanthanide salts are hydrated, possibly providing enough water to 
create the hydroxide precursor to the dimers [28]. The hydroxides are then interchanged with the terephthalic acid and create the dimers shown in Figure 1a.

Unlike most 3d-4f MOFs formed using the reactivities of different functional groups, terephthalic acid only has carboxylic acid functional groups which bind to both the copper ion and the lanthanide ions. The terephthalic acid bridges each lanthanide dimer square planar copper center in an alternating fashion creating a 1-D chain as shown in Figure 2. A similar MOF was discovered by Luo et al. with gadolinium dimers separated by copper ions with a distorted square planar geometry partly contributing to the rod-shaped substructures [29].

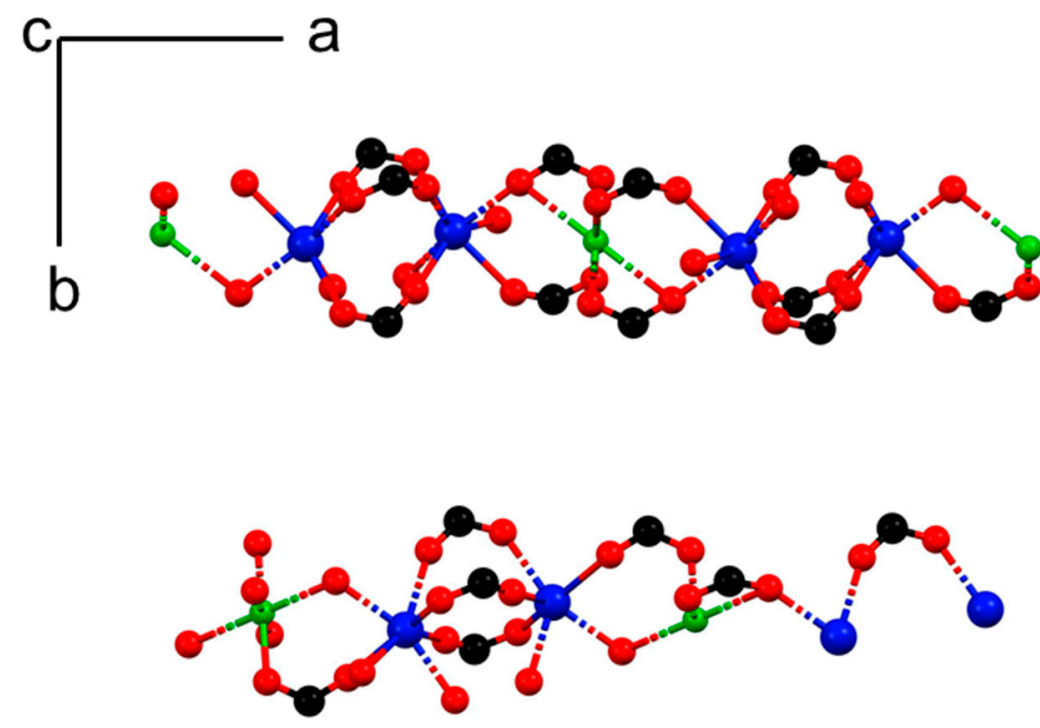

Figure 2. View of the 1-D chain growing along the a-axis featured in the structure of Compound 1 . The colors for elements are as follows: gadolinium (blue), copper (green) oxygen (red), and carbon (black).

In the extended view of compound 1 along the a-axis, as shown in Figure 3, the potential pores of the structure are shown. Figure 3a demonstrates how the free DMF and coordinated DMF face towards the pores of the 3-D structure. Figure $3 \mathrm{~b}$ shows the presence of potential pores within the structure with the absence of the coordinated and free DMF. The extended structure of the MOF and the 1-D pores are highlighted in Figure 3c. 


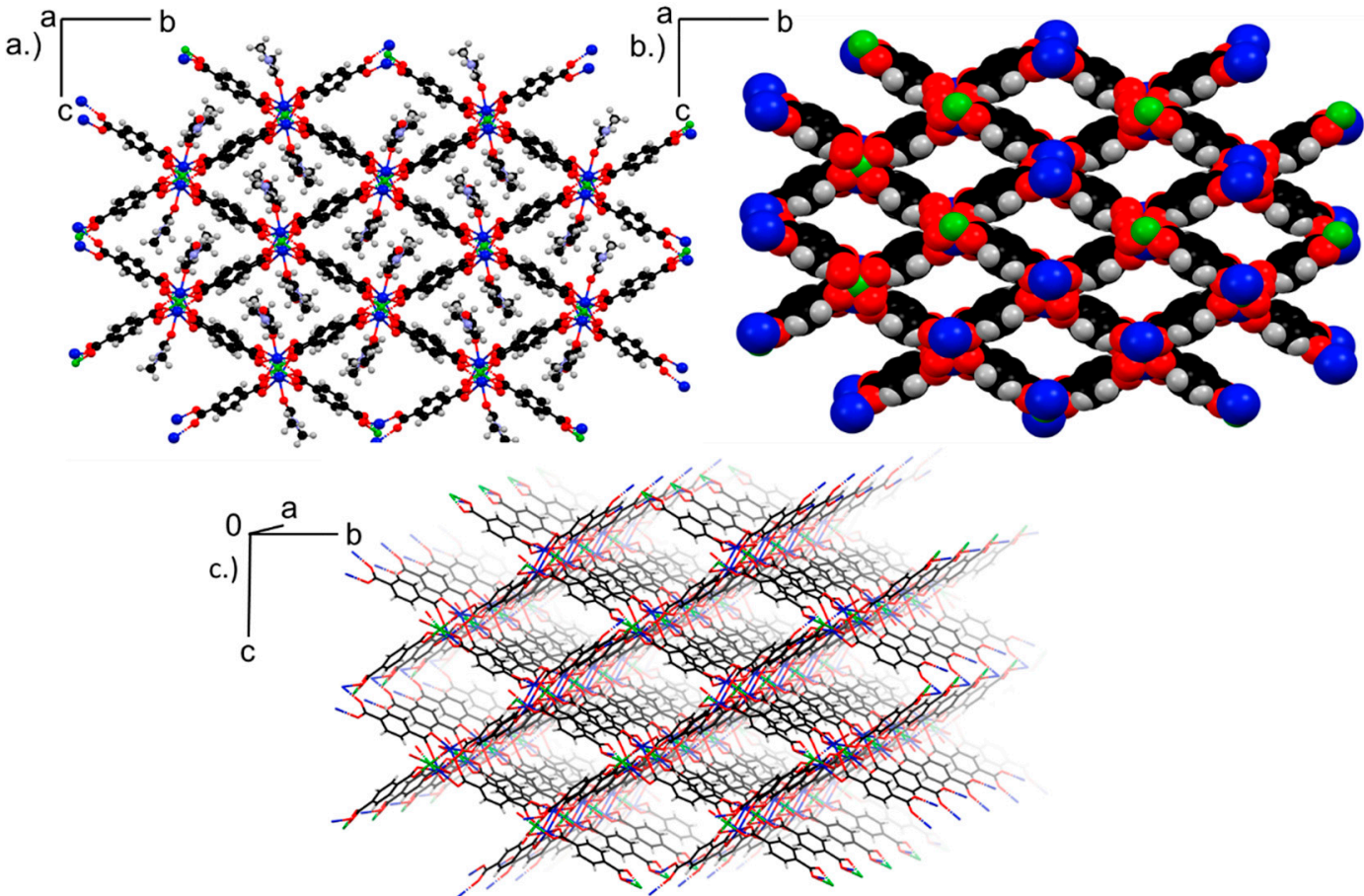

Figure 3. The extended view along the a-axis of compound 1, with (a) showing the DMF present in the pores, (b) showing the DMF removed with a space-filled view, and (c) showing a perspective view highlighting the 1-D channels. The colors for elements are as follows: gadolinium (blue), copper (green) oxygen (red), carbon (black), nitrogen (purple), hydrogen (white).

\subsection{Powder X-ray Diffraction (PXRD)}

\subsubsection{PXRD Comparison of $\mathbf{1}, \mathbf{2}, \mathbf{3}$, and $\mathbf{4}$}

Figure 4 shows the comparison of the powder XRD patterns for the experimental data and simulated from the CIF file. The lack of extra peaks in comparison to the simulated pattern suggests that the crystalline phases $(\mathbf{1}, \mathbf{2}, \mathbf{3}$, and $\mathbf{4})$ are reasonably pure. There are no additional crystalline phases apparent on the PXRD.

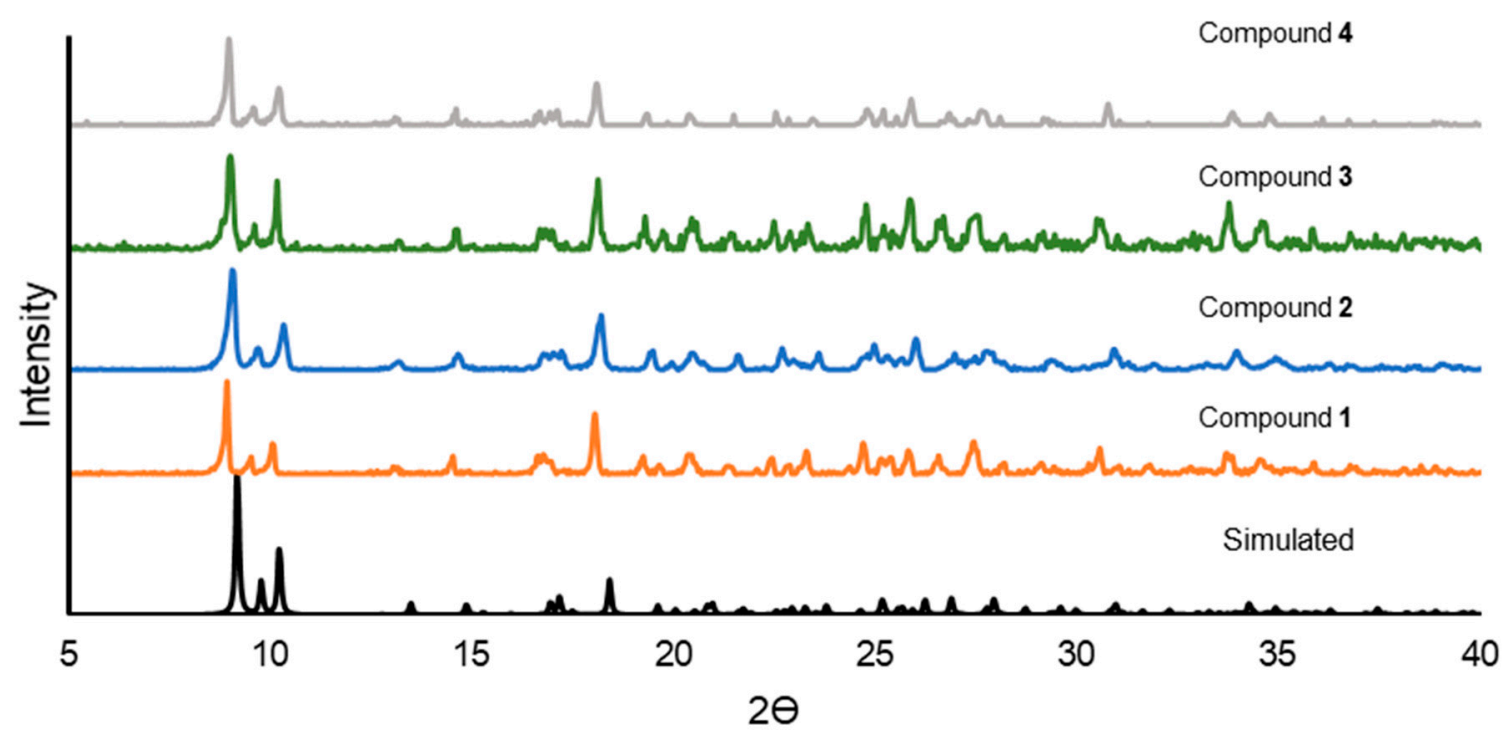

Figure 4. A comparison between the simulated PXRD from the single crystal data of compound 1, and the experimental PXRDs of compounds 1, 2, 3, and 4. 


\subsubsection{PXRD Comparison of the Solvent Removal and Replacement in $\mathbf{1}, \mathbf{2}, \mathbf{3}$, and $\mathbf{4}$}

The X-ray diffraction pattern shown in Figure 5 shows a change in crystal structure after compound 2 was heated to $423 \mathrm{~K}$ in a vacuum oven in order to remove the DMF. There is a small color change in the sample, going from a sky blue to a pale blue, with an associated structural change. The three peaks at 8.88, 9.48, and 10.04 degrees are reduced to two peaks at 9.48 and 10.32. However, as seen in Figure 5, the original structure can be recovered with the addition of DMF. The third peak is regained, although the three peaks are not as distinct. This suggests that the structure does not collapse completely upon removal of the coordinated DMF and can be regained. Compounds 1, 3, and 4 experience the same structural change with the loss of coordinated solvent. Compound 4 in Figure S4, shows the same recovery of the structure with the addition of solvent. While there is a loss of crystallinity as the peaks broaden when activated for 4 , the three peaks at $8.96,9.60$, and 10.20 are not lost. However, Figures S2 and S3 show that $\mathbf{1}$ and $\mathbf{3}$ do not have the same recovery in structure once solvent is added to the material again. Both activated structures show a change in phase losing one of the three peaks around $10^{\circ}$. Interestingly, enough, the MOFs containing the heavier lanthanides, $\mathrm{Ho}^{3+}$ and $\mathrm{Dy}^{3+}$, were able to recover the original phase while the lighter lanthanides were not. This might be due to the heavier lanthanides having smaller ionic radii and greater ionic potential allowing for more stability and interaction with DMF.

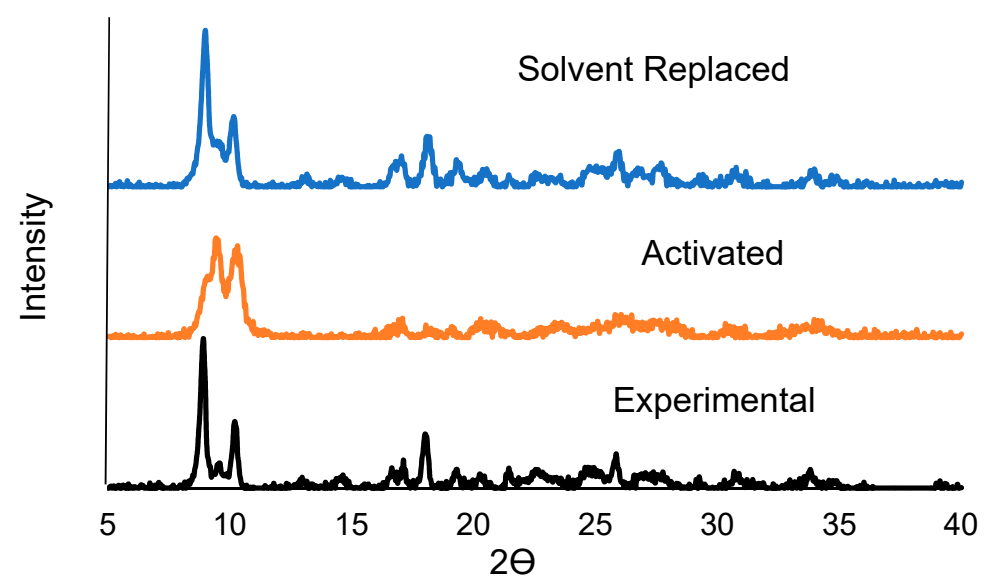

Figure 5. The comparison of the PXRD of the experimental, activated sample ( $423 \mathrm{~K})$, and the solvent replaced for compound 2 .

\subsection{Thermogravimetric Analysis (TGA)}

The TGA for 2 was taken in air from room temperature to $1073 \mathrm{~K}$. There is a steep initial loss of $5 \%$ of the weight at $389 \mathrm{~K}$, as seen in Figure 6 . This indicates the loss of free DMF that is in the pores, as calculated from the molar mass. The amount of free DMF in the structure, one DMF molecule per unit cell, is $5 \%$ of the weight. After this, there is a slow loss of $20 \%$ of the weight from temperatures 389 to $588 \mathrm{~K}$. Most of the weight lost is the DMF that is bound to the Gd. At this point, there is a steep drop in weight signifying the breaking of the Ho-O bonds and $\mathrm{Cu}-\mathrm{O}$ bonds. As shown in Figure S5, compounds 1, 3, and 4, which have the same structure, exhibit similar thermal behavior. While 4 does not show the same steep loss of weight, it shows a more gradual loss of weight at the same temperatures. The weight loss for 4 is about $5 \%$ more than the other three structures. This is possibly due to the presence of amorphous materials. The sample shows the combination diamond-shaped single crystals and highly twinned clusters that could contain an amorphous phase. This additional material could also account for the more gradual loss of weight shown for 4 in Figure S5. 


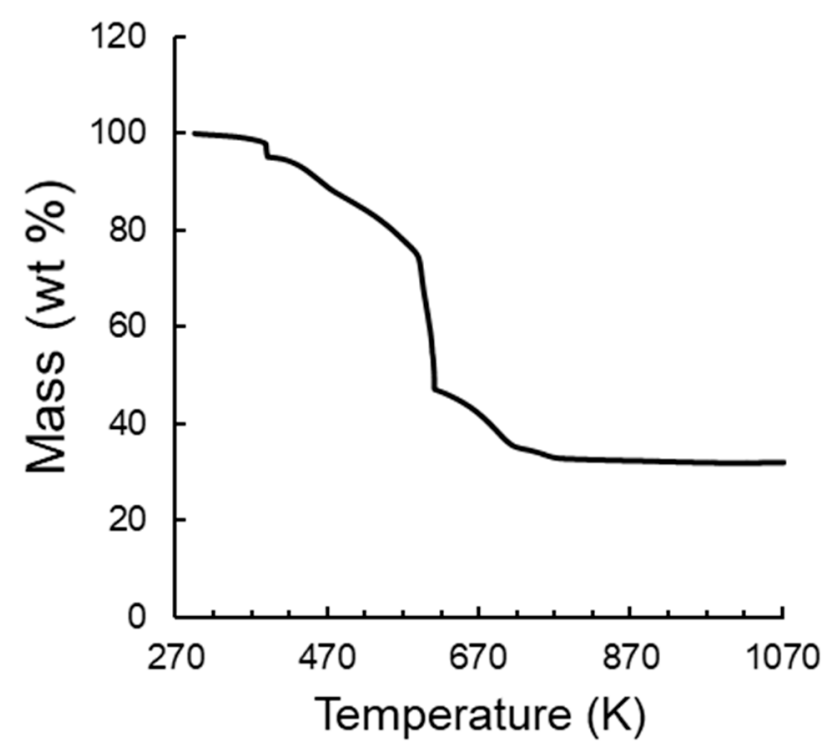

Figure 6. The TGA of compound 2 from room temperature to $1073 \mathrm{~K}$ under air.

\subsection{Luminescence}

Europium (III) is known for being fluorescent. There are several bands of luminescence that result for ${ }^{5} \mathrm{D}_{0}$ to ${ }^{7} \mathrm{~F}_{\mathrm{J}}$ excitation states. However, these are not present in 3 . This is due to how copper quenches this fluorescence when present in the same complex. This is seen in Sakamoto et al., who compared fluorescence spectra for $\mathrm{Eu}\left(\mathrm{NO}_{3}\right)_{3} 6 \mathrm{H}_{2} \mathrm{O}$ to a nickeleuropium complex and a copper-europium complex. The copper-europium complex showed complete quenching of the fluorescence of the europium by the copper. This is due to coupling of the two metal centers allowing the copper to quench the europium [30]. There is also an overlap with the absorbance band of the $\mathrm{d}-\mathrm{d}$ band of $\mathrm{Cu}(\mathrm{II})$ ions and emission of the $\mathrm{Eu}(\mathrm{III})$ ions [31].

\subsection{Magnetism}

The direct current (dc) magnetic susceptibilities of compounds 1, 2, 3, and 4 were studied under an applied magnetic field of $1000 \mathrm{Oe}$ and a temperature range of $2 \mathrm{~K}$ to $300 \mathrm{~K}$, as seen in Figure 7. Compound $\mathbf{1}$ has a magnetic susceptibility of $0.0308 \mathrm{~cm}^{3} / \mathrm{mol}$ at $300 \mathrm{~K}$. There is a gradual increase in magnetic moment as the temperature decreases. Once the temperature reaches $50 \mathrm{~K}$, the magnetic moment begins to sharply increase, characteristic of paramagnetic behavior. Compound 2 has a magnetic susceptibility of $0.0181 \mathrm{~cm}^{3} / \mathrm{mol}$ at $300 \mathrm{~K}$. It has a gradual increase until $50 \mathrm{~K}$ where there is a sharp increase. Framework 4 has a magnetic susceptibility of $0.0326 \mathrm{~cm}^{3} / \mathrm{mol}$ at $300 \mathrm{~K}$. It also has a gradual increase in susceptibility until around $50 \mathrm{~K}$, where it begins to sharply increase. All four frameworks exhibit this characteristic behavior of paramagnetic materials where when the temperature decreases the electrons align with the magnetic field. As such, the inverse of the magnetic susceptibility and temperature follows the Curie-Weiss law. The linear line of best fit from temperatures $2 \mathrm{~K}-200 \mathrm{~K}$ for compound 1 gives a Weiss constant of $\theta=-29.179 \mathrm{~K}$. The linear line of best for compound 2 from temperatures $2 \mathrm{~K}-151 \mathrm{~K}$, gives a Weiss constant of $\theta=-10.560 \mathrm{~K}$. The linear line of best fit for 4 from temperatures $2 \mathrm{~K}-250 \mathrm{~K}$ gives a Weiss Constant of $\theta=-16.330 \mathrm{~K}$. As all of the Weiss constants are negative, they demonstrate varying degrees of antiferromagnetic coupling. 


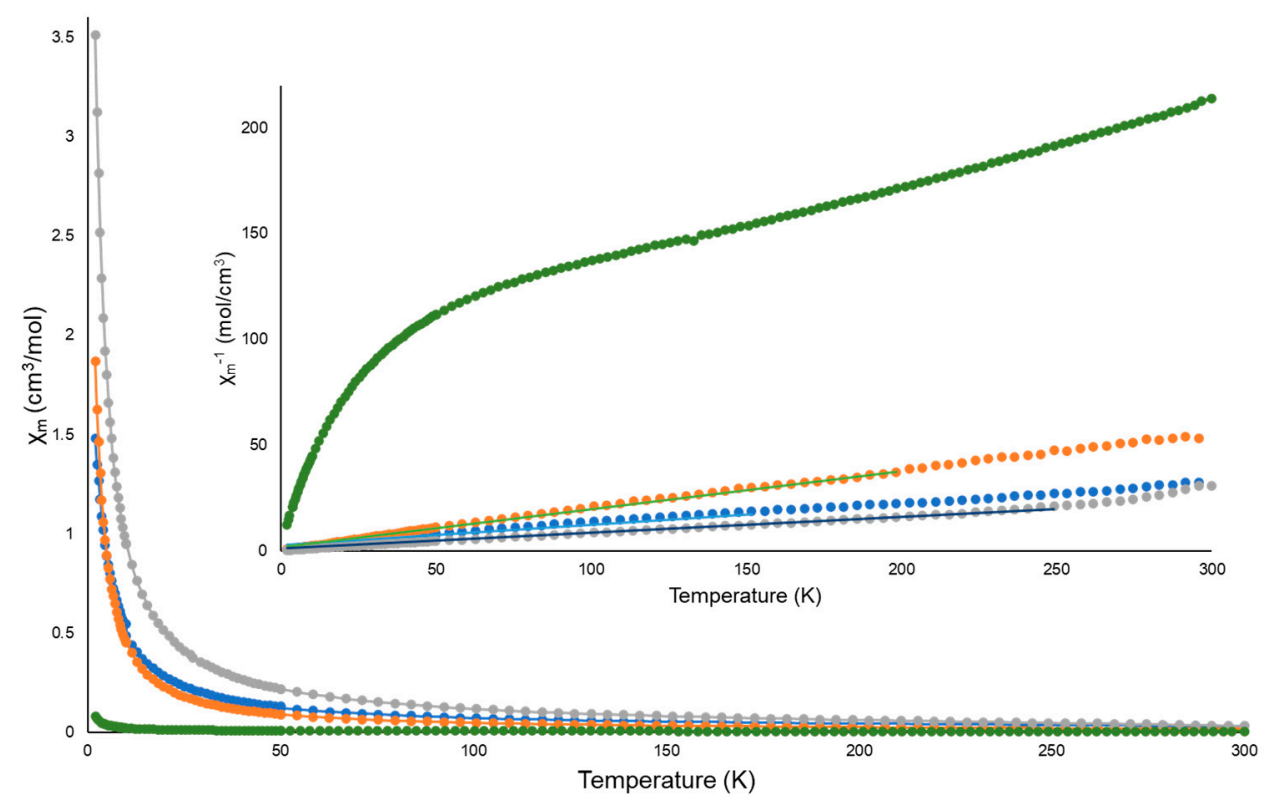

Figure 7. The $\chi_{\mathrm{mvT}}$ of 1 (orange), 2 (blue), 3 (grey), and 4 (green). The insert graph depicts the $\chi_{\mathrm{m}}{ }^{-1} \mathrm{vT}$ graph of $\mathbf{1}$ (orange), $\mathbf{2}$ (blue), $\mathbf{3}$ (grey), and $\mathbf{4}$ (green). The line of best fit for $\mathbf{1}$ (light green), $\mathbf{2}$ (light blue), and 4 (dark blue) are also shown in the insert.

Theoretically the magnetic susceptibility of ground state of $\mathrm{Eu}^{3+},{ }^{7} \mathrm{~F}_{0}$, is zero, as it is non-magnetic [32]. However, there is a slight paramagnetic susceptibility, as shown in Figure 7, with a magnetic susceptibility of $0.0047 \mathrm{~cm}^{3} / \mathrm{mol}$. This non-zero susceptibility of 3 is likely due to the lone free electron of $\mathrm{Cu}^{2+}$, possible lanthanide impurities, or excitation of ${ }^{7} \mathrm{~F}_{0}$ to the ${ }^{7} \mathrm{~F}_{1}$ state through Zeeman perturbation [33]. This results in a material that has a very low magnetic susceptibility in comparison to the other three MOFs.

Many MOFs that contain similar lanthanide dimers have weak ferromagnetic or antiferromagnetic interactions at cryogenic temperatures [34-36]. For example, Almáši et al. studied the effect of solvent exchange had on the distance between the $\mathrm{Gd}^{3+}$ ions and magnetic properties in MOF-76. As the distance between the $\mathrm{Gd}^{3+}$ ions decreased, the magnetic interactions transformed from having ferromagnetic to antiferromagnetic properties [30]. Similar dimers are found with MOFs containing $\mathrm{Ho}^{3+}$, which are also known to have antiferromagnetic coupling [33,37]. These interactions were most likely made possible through super exchange mechanisms through the ligand.

Magnetic coupling between the copper and lanthanides is typical [38]. Ferromagnetic coupling found between lanthanides and copper ions occurs due to overlap of orbitals [39]. This ordering normally occurs at very low temperatures $(2 \mathrm{~K})$, with very few $3 \mathrm{~d}-4 \mathrm{f}$ polymers having higher $\mathrm{T}_{\mathrm{C}}$ values [40]. These interactions are often overshadowed by the magnetic interactions of the lanthanide dimer. As the lanthanide dimer has more unpaired electrons verses the copper's one unpaired electron.

\section{Conclusions}

In conclusion, a new crystal structure of a mixed metal MOF was discovered with four isostructures containing four lanthanide ions, $\mathrm{Gd}^{3+}, \mathrm{Ho}^{3+}, \mathrm{Eu}^{3+}$, and $\mathrm{Dy}^{3+}$, and one $\mathrm{Cu}^{2+}$ ion. The MOF structure undergoes a reversible change upon removal and addition of DMF solvent. All four different MOFs were determined to have varying degrees of antiferromagnetic interactions.

Supplementary Materials: The following are available online at https: / /www.mdpi.com/article / 10.3390/cryst11121547/s1, Figure S1: The asymmetrical view of 1, 2, 3, and 4. Figure S2: The comparison of the activated and solvent replaced PXRDs of compound 1, Figure S3: The comparison 
of the activated and solvent replaced PXRDs of compound 3, Figure S4: The comparison of the activated and solvent replaced PXRDs of compound 4, Figure S5: The TGA for compound 3, 4, and 1.

Author Contributions: Conceptualization, M.L.M. and K.J.B.J.; methodology, M.L.M.; validation, M.L.M., and K.J.B.J.; formal analysis, M.L.M.; single crystal analysis, G.M.; investigation, M.L.M.; data curation, M.L.M. and A.L.L.; writing—original draft preparation, M.L.M. and G.M.; writingreview and editing, M.L.M. and K.J.B.J.; visualization, M.L.M. and K.J.B.J.; supervision, K.J.B.J.; project administration, K.J.B.J.; funding acquisition, K.J.B.J. All authors have read and agreed to the published version of the manuscript.

Funding: This research is funded by the Robert a Welch Foundation (Grant No. At 1153).

Institutional Review Board Statement: Not applicable.

Informed Consent Statement: Not applicable.

Data Availability Statement: The crystallographic data is available in the Cambridge Crystallographic Data Center.

Acknowledgments: The authors acknowledge support from the Robert a Welch Foundation (Grant No. At 1153). We also thank Juan P. Vizuet for his advice and discussions.

Conflicts of Interest: The authors declare no conflict of interests.

\section{References}

1. Zhao, Z.; Li, Z.; Lin, Y.S. Adsorption and Diffusion of Carbon Dioxide on Metal-Organic Framework (MOF-5). Ind. Eng. Chem. Res. 2009, 48, 10015-10020. [CrossRef]

2. Rice, A.M.; Leith, G.A.; Ejegbavwo, O.A.; Dolgopolova, E.A.; Shustova, N.B. Heterometallic Metal-Organic Frameworks (MOFs): The Advent of Improving the Energy Landscape. ACS Energy Lett. 2019, 4, 1938-1946. [CrossRef]

3. Dhakshinamoorthy, A.; Asiri, A.M.; Garcia, H. Mixed-Metal or Mixed-Linker Metal Organic Frameworks as Heterogeneous Catalysts. J. Adv. Catal. Sci. 2016, 6, 5238-5261. [CrossRef]

4. Assen, A.H.; Yassine, O.; Shekhah, O.; Eddaoudi, M.; Salama, K.N. MOFs for the Sensitive Detection of Ammonia: Deployment of Fcu-MOF Thin Films as Effective Chemical Capacitive Sensors. ACS Sens. 2017, 2, 1294-1301. [CrossRef] [PubMed]

5. Miner, E.M.; Park, S.S.; Dincă, M. High $\mathrm{Li}^{+}$and $\mathrm{Mg}^{2+}$ Conductivity in a Cu-Azolate Metal-Organic Framework. J. Am. Chem. Soc. 2019, 141, 4422-4427. [CrossRef] [PubMed]

6. Black, C.A.; Costa, J.S.; Fu, W.T.; Massera, C.; Roubeau, O.; Teat, S.J.; Aromí, G.; Gamez, P.; Reedijk, J. 3-D Lanthanide MetalOrganic Frameworks: Structure, Photoluminescence, and Magnetism. Inorg. Chem. 2009, 48, 1062-1068. [CrossRef] [PubMed]

7. Masoomi, M.Y.; Morsali, A.; Dhakshinamoorthy, A.; Garcia, H. Mixed-Metal MOFs: Unique Opportunities in Metal-Organic Framework (MOF) Functionality and Design. Angew. Chem. 2019, 58, 15188-15205. [CrossRef] [PubMed]

8. Wu, Z.-L.; Dong, J.; Ni, W.-Y.; Zhang, B.-W.; Cui, J.-Z.; Zhao, B. Unique Chiral Interpenetrating d-f Heterometallic MOFs as Luminescent Sensors. Inorg. Chem. 2015, 54, 5266-5272. [CrossRef]

9. Cui, Z.; Zhang, X.; Liu, S.; Zhou, L.; Li, W.; Zhang, J. Anionic Lanthanide Metal-Organic Frameworks: Selective Separation of Cationic Dyes, Solvatochromic Behavior, and Luminescent Sensing of Co(II) Ion. Inorg. Chem. 2018, 57, 11463-11473. [CrossRef]

10. Sakamoto, M. d-f Heteronuclear Complexes: Synthesis, Structures and Physicochemical Aspects. Coord. Chem. Rev. 2001, 219-221, 379-414. [CrossRef]

11. Shiga, T.; Onuki, T.; Matsumoto, T.; Nojiri, H.; Newton, G.N.; Hoshino, N.; Oshio, H. Undecanuclear Mixed-Valence 3d-4f Bimetallic Clusters. Chem. Comm. 2009, 3568-3570. [CrossRef] [PubMed]

12. Li, Z.-Y.; Wang, Y.-X.; Zhu, J.; Liu, S.-Q.; Xin, G.; Zhang, J.-J.; Huang, H.-Q.; Duan, C.-Y. Three Series of 3d-4f Heterometallic Polymers Based on [LnCu6] or [Ln6Cu24] Clusters and Formate Bridges: Displaying Significant Magnetocaloric Effect. Cryst. Growth Des. 2013, 13, 3429-3437. [CrossRef]

13. Prasad, T.K.; Rajasekharan, M.V.; Costes, J.-P. A Cubic 3d-4f Structure with Only Ferromagnetic Gd-Mn Interactions. Angezw. Chem. Int. Ed. Engl. 2007, 119, 2909-2912. [CrossRef]

14. He, H.; Ma, H.; Sun, D.; Zhang, L.; Wang, R.; Sun, D. Porous Lanthanide-Organic Frameworks: Control over Interpenetration, Gas Adsorption, and Catalyst Properties. Cryst. Growth Des. 2013, 13, 3154-3161. [CrossRef]

15. Abednatanzi, S.G.; Derakhshandeh, P.V.D.; Depauw, H.; Coudert, F.-X.; Vrielinck, H.; Voort, P.; Leus, K. Mixed-Metal MetalOrganic Frameworks. Chem. Soc. Rev. 2019, 48, 2535-2565. [CrossRef] [PubMed]

16. Zhang, F.; Zou, X.; Yan, P.; Sun, J.; Hou, G.; Li, G. Pyrazine-2,3-Carboxylate Based Ag Homometallic and $\mathrm{Ln}^{3+}-\mathrm{Ag}^{+} \mathrm{Heterometallic}^{-}$ Coordination Frameworks: Synthesis, Structures, and Magnetic Properties. Cryst. Growth Des. 2015, 15, 1249-1258. [CrossRef]

17. Rieter, W.J.; Taylor, K.M.L.; An, H.; Lin, W.; Lin, W. Nanoscale Metal-Organic Frameworks as Potential Multimodal Contrast Enhancing Agents. J. Am. Chem. Soc. 2006, 128, 9024-9025. [CrossRef] [PubMed]

18. Bresinska, I.; Balkus, K.J.J. Studies of Gd(III)-Exchanged Y-Type Zeolites Relevant to Magnetic Resonance Imaging. J. Phys. Chem. 1994, 98, 12989-12994. [CrossRef] 
19. Young, S.W.; Qing, F.; Rubin, D.; Balkus, K.J.; Engel, J.S.; Lang, J.; Dow, W.C.; Mutch, J.D.; Miller, R.A. Gadolinium Zeolite as an Oral Contrast Agent for Magnetic Resonance Imaging. J. Magn. Reson. Imaging 1995, 5, 499-508. [CrossRef] [PubMed]

20. Peller, M.; Böll, K.; Zimpel, A.; Wuttke, S. Metal-Organic Framework Nanoparticles for Magnetic Resonance Imaging. Inorg. Chem. Front. 2018, 5, 1760-1779. [CrossRef]

21. Balkus, K.J.; Coutinho, D.; Lucas, J.; Washmon-Kriel, L. Synthesis and Characterization of DAM-1 Type Materials. MRS Proc. 2000, 628, 2000. [CrossRef]

22. Allendorf, M.D.; Medishetty, R.; Fischer, R.A. Guest Molecules as a Design Element for Metal-Organic Frameworks. MRS Bull. 2016, 41, 865-869. [CrossRef]

23. Kitagawa, S.; Kitaura, R.; Noro, S.-I. Functional Porous Coordination Polymers. Angew. Chem. Int. Ed. Engl. 2004, 43, 2334-2375. [CrossRef] [PubMed]

24. Sheldrick, G.M. Integrated space-group and crystal-structure determination. Acta Crystallogr. Sect. A 2015, 71, 3-8. [CrossRef]

25. Sheldrick, G.M. Crystal structure refinement with SHELXL. Acta Crystallogr. Sect. C 2015, 71, 3-8. [CrossRef] [PubMed]

26. Andrews, P.C.; Gee, W.J.; Junk, P.C.; Massi, M. Variation of Structural Motifs in Lanthanoid Hydroxo Clusters by Ligand Modification. New J. Chem. 2013, 37, 35-48. [CrossRef]

27. Baskar, V.; Roesky, P.W. Synthesis and Structural Characterization of a Series of Tetranuclear Lanthanide Clusters. Z. Anorg. Allg. Chem. 2005, 631, 2782-2785. [CrossRef]

28. Zheng, Z. Ligand-Controlled Self-Assembly of Polynuclear Lanthanide-Oxo/Hydroxo Complexes: From Synthetic Serendipity to Rational Supramolecular Design. Chem. Comm. 2001, 24, 2521-2529. [CrossRef]

29. Luo, F.; Yang, Y.-T.; Che, Y.-X.; Zheng, J.-M. Construction of Cu(II)-Gd(III) Metal-Organic Framework by the Introduction of a Small Amino Acid Molecule: Hydrothermal Synthesis, Structure, Thermostability, and Magnetic Studies. Cryst. Eng. Comm. 2008, 10, 1613. [CrossRef]

30. Sakamoto, M.; Hashimura, M.; Nakayama, Y.; Matsumoto, A.; Okawa, H. Fluorescence Quenching of Europium(III) by Heteronuclear Complex Formation with Copper(II) or Nickel(II). Bull. Chem. Soc. Jpn. 1992, 65, 1162-1164. [CrossRef]

31. Ohtsu, H.; Suzuki, T.; Ohtsuka, H.; Ishii, A.; Hasegawa, M. The Unprecedented Role of a Cu(II) Cryptand in the Luminescence Properties of a Eu(III) Cryptate Complex. Monatsh. Chem. 2009, 140, 783-787. [CrossRef]

32. Petrochenkova, N.V.; Tkachenko, I.A.; Mirochnik, A.G.; Karasev, V.E.; Kavun, V.Y. Luminescence and Magnetic Properties of Europium(III) Carboxylatodibenzoylmethanates. Opt. Spectrosc. 2010, 109, 917-920. [CrossRef]

33. Andruh, M.; Bakalbassis, E.; Kahn, O.; Trombe, J.C.; Porcher, P. Structure, Spectroscopic and Magnetic Properties of Rare Earth Metal(III) Derivatives with the 2-Formyl-4-Methyl-6-(N-(2-Pyridylethyl)Formimidoyl)Phenol Ligand. Inorg. Chem. 1993, 32, 1616-1622. [CrossRef]

34. Almáši, M.; Zeleňák, V.; Zeleňáková, A. Magnetic and Structural Studies into the Effect of Solvent Exchange Process in MetalOrganic Framework MOF-76(Gd). Acta Phys. Pol. A 2017, 131, 991-993. [CrossRef]

35. Lin, Z.-J.; Xu, B.; Liu, T.-F.; Cao, M.-N.; Lü, J.; Cao, R. A Series of Lanthanide Metal-Organic Frameworks Based on Biphenyl3,4',5-Tricarboxylate: Syntheses, Structures, Luminescence and Magnetic Properties. Eur. J. Inorg. Chem. 2010, 2010, 3842-3849. [CrossRef]

36. Fernández, B.; Oyarzabal, I.; Seco, J.M.; Sebastián, E.S.; Fairen-Jiménez, D.; Gómez-Ruiz, S.; Salinas-Castillo, A.; Calahorro, A.J.; Rodríguez-Diéguez, A. Luminescence and Magnetic Properties of Two Three-Dimensional Terbium and Dysprosium MOFs Based on Azobenzene-4,4'-Dicarboxylic Linker. Polymers 2016, 8, 39. [CrossRef]

37. Li, Z.; Zhu, G.; Guo, X.; Zhao, X.; Jin, Z.; Qiu, S. Synthesis, Structure, and Luminescent and Magnetic Properties of Novel Lanthanide Metal-Organic Frameworks with Zeolite-like Topology. Inorg. Chem. 2007, 46, 5174-5178. [CrossRef] [PubMed]

38. Tang, Y.; Guo, W.; Zhang, S.; Yang, M.; Xiang, H.; He, Z. $\mathrm{Gd}_{2} \mathrm{Cu}\left(\mathrm{SO}_{4}\right)_{2}(\mathrm{OH})_{4}$ : A 3d-4f Hydroxysulfate with an Enhanced Cryogenic Magnetocaloric Effect. Dalton Trans. 2015, 44, 17026-17029. [CrossRef]

39. Benelli, C.; Caneschi, A.; Gatteschi, D.; Guillou, O.; Pardi, L. Synthesis, Crystal Structure, and Magnetic Properties of Tetranuclear Complexes Containing Exchange-Coupled $\mathrm{Ln}_{2} \mathrm{Cu}_{2}$ (Ln: Gd, Dy) Species. Inorg. Chem. 1990, 29, 1750-1755. [CrossRef]

40. Pascual-Álvarez, A.; Cano, J.; Lloret, F.; Ferrando-Soria, J.; Armentano, D.; Pardo, E. Magnetic Order in a Cu(II)-Dy(III) Oxamato-Based Two-Dimensional Coordination Polymer. C. R. Chim. 2019, 22, 466-475. [CrossRef] 